\title{
Landscaping of Residential Estates as a Mitigation Measure to Reduce Carbon Dioxide and Temperature Levels in Inner Ibadan City, Nigeria
}

\author{
Tejumola Adesoye ${ }^{1}$, Mynepalli Kameswara Chandra Sridhar ${ }^{2}$, Akinwale Oladotun Coker ${ }^{1}$, \\ Mumuni Adejumo ${ }^{2, *}$ \\ ${ }^{1}$ Department of Civil Engineering, University of Ibadan, Ibadan, Nigeria \\ ${ }^{2}$ Department of Environmental Health Sciences, College of Medicine, University of Ibadan, Ibadan, Nigeria

\section{Email address:} \\ adesoye.teju@gmail.com (T. Adesoye),mkcsridhar@gmail.com (M. K. C. Sridhar), cokerwale@yahoo.com (A. O. Coker), \\ adejumo_mumuni@yahoo.com (M. Adejumo) \\ ${ }^{*}$ Corresponding author
}

\section{To cite this article:}

Tejumola Adesoye, Mynepalli Kameswara Chandra Sridhar, Akinwale Oladotun Coker, Mumuni Adejumo. Landscaping of Residential Estates as a Mitigation Measure to Reduce Carbon Dioxide and Temperature Levels in Inner Ibadan City, Nigeria. International Journal of Environmental Monitoring and Analysis. Vol. 7, No. 5, 2019, pp. 93-102. doi: 10.11648/j.ijema.20190705.11

Received: June 18, 2019; Accepted: August 12, 2019; Published: September 29, 2019

\begin{abstract}
This study assessed the spatial distribution of carbon dioxide emanation in selected residential estates and the impact of landscaping in reducing their levels in Ibadan metropolis. The study was carried out in high, medium and low commercial activity areas characterized by population density and traffic congestion within Ibadan city. $\mathrm{CO}_{2}$ concentrations and temperature were measured at 4 hourly interval from $9 \mathrm{am}$ to $5 \mathrm{pm}$ for a period of seven consecutive days while numbers of trees/plants (biomass density) were counted, at 21 different points from seven areas each with high, medium and low commercial activities. Measurements were carried out with the aid of calibrated portable gas meters. The means $\mathrm{CO}_{2}(\mathrm{ppm})$ were $542 \pm 95,415 \pm 11$ and $376 \pm 14$ at $1.00 \mathrm{pm}$ in the high, medium and low commercial activity areas respectively. $\mathrm{CO}_{2}$ concentrations were generally higher than IPCC value, but highest in the afternoon. Temperature values were generally higher in the afternoon in high and medium commercial activity areas, but lower in the low commercial activity zones. Significantly, density of trees in low commercial activity areas (234.3 \pm 6.7$)$ was higher compared to those in medium (22.8 \pm 0.5$)$ and high (24.2 \pm 0.7$)$ activity areas respectively. An inverse correlation was observed between $\mathrm{CO}_{2}$ concentration and the density of trees $(\mathrm{r}=-0.456 ; \mathrm{p}=0.038)$. The spatial distribution of $\mathrm{CO}_{2}$ concentration in relation to landscaping revealed that $\mathrm{CO}_{2}$ concentration reduces northward away from the urban core areas where there were fewer trees. The areas with low commercial activities had large numbers of trees while temperature and $\mathrm{CO}_{2}$ flux were lower in these areas. Temperature and density of trees contribute significantly in explaining the $\mathrm{CO}_{2}$ concentration $(\mathrm{p}=0.015) . \mathrm{CO}_{2}$ concentrations and temperature were high in high commercial activities areas in Ibadan metropolis, few or no trees were observed in those areas. Increase in density of trees could be attributed to decrease in the $\mathrm{CO}_{2}$ concentration. Hence, tree planting needs to be encouraged in the urban core of Ibadan metropolis to reduce air pollution.
\end{abstract}

Keywords: Spatial Distribution, Carbon Dioxide Level, Temperature, Ibadan Metropolis, Landscape

\section{Introduction}

Pollution can be defined as a disorder within an environment which is a by-product of energy conversion and resources usage [1]. It was defined as a contamination and or reduction in the value of an object, especially by adding harmful or unpleasant substances to it $[2,3]$. Air pollution is any atmospheric condition in which substances are present at concentrations higher than their normal ambient levels and produces a measurable effect on man, animals, vegetation, or materials [4]. Studies have reported that emissions from vehicles and other forms of transportation technologies were responsible for about $22 \%$ particulate matter, $77 \%$ carbon monoxide, about $80-90 \%$ nitrate and $36 \%$ volatile organic 
compounds $[5,6]$. These air pollutants are on the rise in urban areas due to increase in pollution levels from various channels, thereby, posing great risk to the ecosystem health. In Nigeria, apart from industrial pollutants there is increased pollution from mobile sources with per capita increase in vehicle ownership [7].

Carbon dioxide $\left(\mathrm{CO}_{2}\right)$ is the most abundant of the minor atmospheric gases, due to its solubility; it is about $98 \%$ of the total dissolved carbon in the ocean-atmosphere system. It undergoes a series of reactions depending on the $\mathrm{pH}$ of the system for its transformation to bicarbonates and/or carbonic ions [8]. Furthermore, it plays an important greenhouse gas role in the absorption of infrared radiation from the earth, thereby, regulates the earth's climate. The increase in atmospheric $\mathrm{CO}_{2}$ is brought about by varieties of anthropogenic activities [9, 10]. These activities include, but not limited to, cement production, deforestation, fossil fuels combustion, open burning of refuse, operation of generator sets, and human respiration in congested places $[11,12]$.

According to the findings of a study, there was about $30 \%$ increase in the concentration of atmospheric carbon dioxide after the industrial revolution and an increase of about $1 \%$ per year causing a further growth in its concentration [13-15]. Due to the growth of greenhouse gas effect, this increase contributes to global climate change $[13,16]$. Observations of $\mathrm{CO}_{2}$ in ice cores and direct measurements of $\mathrm{CO}_{2}$ concentrations in the atmosphere demonstrated that $\mathrm{CO}_{2}$ levels increased from around $280 \mathrm{ppm}$ in 1750 to nearly 380 ppm by $2005[13,17]$. It has been predicted that by 2100 global temperatures will increase by as much as $3.1^{\circ} \mathrm{C}$ relative to the 1980-1999 global mean due to increasing levels of atmospheric $\mathrm{CO}_{2}$ [18].

Urbanization or the social and economic modernization of metropolitan cities has attained unprecedented growth [19]. As an inevitable phase of globalization, it has fuelled society's consumption patterns, alongside incessant technological development. Mass production and industrialization, the primary thrusts of the global market, require consumption of non-renewable resources arising from the increase in energy usage. These centers of production are concentrated in urban, highly populated areas. This phase of progress, however, comes at the expense of environmental quality. High levels of carbon emissions are concentrated in areas with high population density. This hampers the natural flow of the ecosystem and consequently a sustainable environment might not be efficiently maintained. As a result of this trend, increase in the density of carbon emissions might potentially harness catastrophic impacts in the future [20]. The impact could possibly possess direct risks (such as inflammation, reduced higher-level cognitive abilities, bone demineralization, kidney calcification, oxidative stress and endothelial dysfunction) to human health [21]. Also, $\mathrm{CO}_{2}$ accumulation can progressively displace oxygen in the air, inducing a mild chronic hypoxaemia with untoward health effects [22].

However, tree planting in cities can contribute significantly to improve human health and environmental quality. In addition, monitoring and quantifying urban vegetative stocks and carbon fluxes have economic, environmental, and social significance, addressing issues of air quality, climate change, and sustainability [23]. Unfortunately, little is known about the urban forest resource and what it contributes to the local and regional society and economy in Nigeria. Poor air quality is ubiquitous in many urban centers, leading to impairment of both human health and landscape, ecosystem damage and impaired visibility [24]. This problem can be alleviated by afforestation. It is with this background that this study therefore is borne out of the need to assess the impact of landscaping on temperature and carbon dioxide in Ibadan urban environment.

\section{Methodology}

\subsection{Study Area}

Ibadan is the capital of Oyo State in southwestern Nigeria. It is located approximately on longitude $30^{\circ} 53^{\prime} \mathrm{E}$ and latitude $7034^{\prime}$ N. Ibadan consists 11 local government areas (LGAs) for governance and administrative purposes. Five of the LGAs are located in the metropolitan core of the city, while the remaining six are either predominantly peri-urban or rural settlements. Ibadan city comprises of five LGAs with an estimated population of about 2,550,593 as of 2006 [25]. With an annual growth rate of $4.14 \%$, the estimated population of Ibadan for 2015 is 3,160,200. A noteworthy feature of the city before 1972 was the absence of high density areas. By 1984, $11.42 \mathrm{~km}^{2}$ of the urban area was classified as high-density which had increased to $64.8 \mathrm{~km}^{2}$ by 2003. With the current density of approximately 2,889 people per square kilometer, Ibadan has one of the highest population densities in Nigeria [25].

The city is projected to increase to about 5.03 million inhabitants by 2025 , considering an average annual growth rate of $4.6 \%$ during the period 2010-2020 [26]. The climate is characterized by a rainy season from March through October, while the dry season stretches from November to February. In addition, about $36.25 \mathrm{~km}^{2}$ (34.9\% of the land area) is devoted to land use (such as residential area, public buildings and facilities, markets, industrial and commercial areas as well as educational institutions), social amenities and open spaces. The remaining $63.75 \mathrm{~km}^{2}$ is devoted to non-urban uses such as forest reserves, farm lands and aquatic environment [27]. Despite its size and density, Ibadan grew originally without a clearly defined master plan like many other urban centers in Nigeria [28]. According to population density, the city can be categorized into high, medium and low density areas. Narrow carriageway, closely-packed residential areas, and indigenous people are the characteristics of this density type. However, this situation differs in the low-density area as it is well-planned with paved road and occupied by high income earners and top civil servants. 


\subsection{Sampling Points and Data Collection}

In view of the large size of the study area, and in order to achieve the objectives of the study, a stratified random technique was used. The sample was drawn from residential areas, markets, forest and gardens, and busy roads as shown in Figure 1.

Concentration of $\mathrm{CO}_{2}$ and temperature at each of the sample locations were measured at 4 hourly intervals between $9.00 \mathrm{am}$ and $5.00 \mathrm{pm}$ for a period of seven consecutive days. Carbon dioxide meter was used for measuring $\mathrm{CO}_{2}$ and temperature level at each sampling points in the study area. In general, $\mathrm{CO}_{2}$ was quantified by direct sensory measurement and intensity, using the carbon meter sense as the $\mathrm{CO}_{2}$ detector. The meter took measurements immediately as it was turned on while readings were updated every second. In the event of a rapid change in operating environment (from high to low temperature), it took approximately two minutes for the $\mathrm{CO}_{2}$ and temperature to adjust and ten minutes for humidity to stabilize.

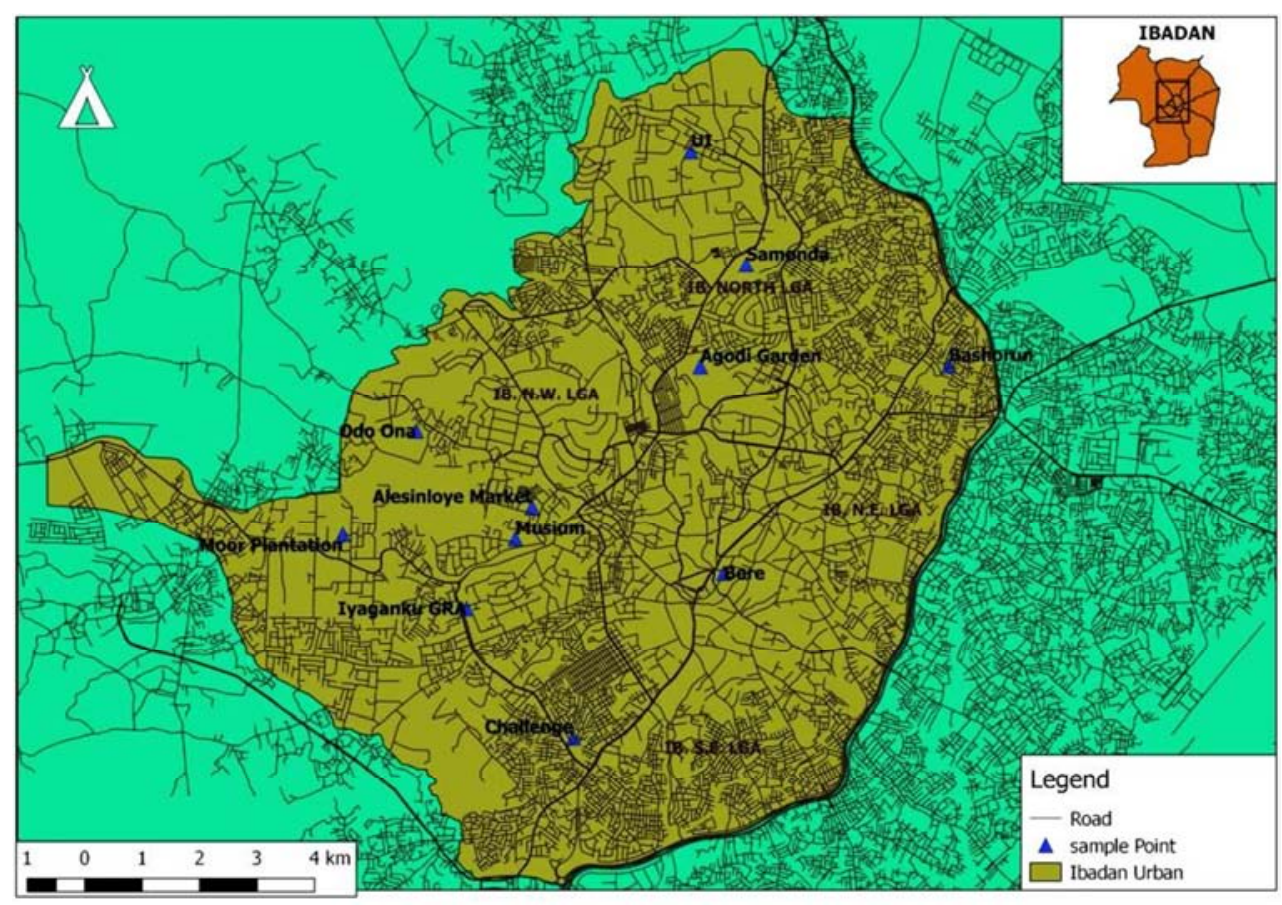

Figure 1. Ibadan Showing Sample Collection Points.

\subsection{Spatial Database Description}

Spatial information and analysis was carried out for detailed understanding of the spatial variation of $\mathrm{CO}_{2}$ and temperature. Information collected includes the geographical background of the areas under study and spatial data related to the waste collection procedure used by the state Ministry of Environment. The researcher monitored the samples of air in the study area. The content of the spatial database is summarized in Table 1.

Table 1. The spatial database - type of data and corresponding geometry.

\begin{tabular}{lll}
\hline Spatial data & Type & Geometry \\
\hline Road network & Vector & Line \\
Land cover/Landscape & Vector & Polygon \\
Local Government area & Vector & Polygon \\
Satellite image from Google Earth & Raster & \\
\hline
\end{tabular}

\subsection{GIS Application: Buffer and Spatial Interpolation Analysis}

The GIS analysis used in this study is thematic classification and query of feature attributes to examine spatial patterns and relationship between $\mathrm{CO}_{2}$ concentration and temperature. This functionality explicitly allowed for exploring spatial relationship at the study site [29]. Furthermore, buffer or proximity analyses mapped the impact zones of vector sampling sites, thereby indicating where control activity needed to be strengthened [30]. This zone was analyzed using the method in which buffer zones of $1000 \mathrm{~m}$ were created around the sampling sites in order to indicate the spread of $\mathrm{CO}_{2}$ [31]. In addition, GIS-based $\mathrm{CO}_{2}$ concentration and temperature mapping-based interpolation techniques such as inverse distance weighting (IDW) and kriging were employed [32]. All the aforementioned GIS applications were adopted in the study.

\subsection{Method of Data Analysis}

The "Analysis Tool Pak" was used in the analysis of the $\mathrm{CO}_{2}$ data collected, one-way ANOVA was done to test for significant differences in the levels of $\mathrm{CO}_{2}$ obtained for different periods at each location while two-way ANOVA was carried out to test the significance of the interaction between period and location. Also, regression model was used to relate $\mathrm{CO}_{2}$ concentration with temperature and number of trees. Level of significance was set at 0.05 . 


\section{Results}

\subsection{Concentration of Carbon Dioxide and Temperature Values}

The findings of carbon dioxide and temperature which were collected at four-hour interval between 9 am and $5 \mathrm{pm}$ is presented in Table 2. The mean concentration of $\mathrm{CO}_{2}$ at a high commercial area was 525 $\pm 91 \mathrm{ppm}, 542 \pm 95 \mathrm{ppm}$ and $535 \pm 90 \mathrm{ppm}$ at $9 \mathrm{am}, 1 \mathrm{pm}$ and $5 \mathrm{pm}$ respectively. At the medium activity area, concentration of $\mathrm{CO}_{2}$ was $407 \pm 12 \mathrm{ppm}$ at $9 \mathrm{am}, 415 \pm 11 \mathrm{ppm}$ at $1 \mathrm{pm}$ and $408 \pm 10 \mathrm{ppm}$ at $5 \mathrm{pm}$. At low activity area, mean concentrations of $\mathrm{CO}_{2}$ at $9 \mathrm{am}, 1 \mathrm{pm}$ and 5 pm were $366 \pm 12 \mathrm{ppm}, \quad 376 \pm 14 \mathrm{ppm}$ and $367 \pm 13 \mathrm{ppm}$ respectively. All the $\mathrm{CO}_{2}$ values were higher than the IPCC values. The mean temperatures at a high commercial area were $30.7 \pm 0.6^{\circ} \mathrm{C}, 31.3 \pm 1.0^{\circ} \mathrm{C}$ and $31.5 \pm 0.8^{\circ} \mathrm{C}$ at $9 \mathrm{am}, 1 \mathrm{pm}$ and $5 \mathrm{pm}$ respectively. At the medium activity area, hourly temperature was $30.4 \pm 0.5^{\circ} \mathrm{C}$ at $9 \mathrm{am}, 31.9 \pm 1.0^{\circ} \mathrm{C}$ at $1 \mathrm{pm}$ and $31.4 \pm 0.8^{\circ} \mathrm{C}$ at $5 \mathrm{pm}$. At low activity area, mean hourly temperature at $9 \mathrm{am}$, $1 \mathrm{pm}$ and $5 \mathrm{pm}$ was $29.3 \pm 0.9^{\circ} \mathrm{C}, 30.4 \pm 0.9^{\circ} \mathrm{C}$ and $29.9 \pm 0.9^{\circ} \mathrm{C}$ respectively. Temperature values were higher than the recommended limits by IPCC. Furthermore, $\mathrm{CO}_{2}$ concentrations were highest in the afternoon when atmospheric temperature is usually highest. The $\mathrm{CO}_{2}$ concentration reduced with levels of commercial activities from high to low. Temperature values were generally higher in the afternoon in medium and high commercial activity areas, but lower in the low commercial activity zones.

Table 2. Concentration of carbon dioxide and temperature values at different area.

\begin{tabular}{llllll}
\hline Level of Commercial & \multicolumn{2}{c}{$\mathbf{C O}_{2}$ concentration (ppm) Mean (SD) } & \multicolumn{3}{c}{ Temperature $\left({ }^{\circ} \mathbf{C}\right)$} \\
\cline { 2 - 6 } Activities & $\mathbf{9 : 0 0}$ AM & $\mathbf{1 : 0 0}$ PM & $\mathbf{5 : 0 0 ~ P M}$ & $\mathbf{9 : 0 0}$ AM & $\mathbf{1 : 0 0}$ PM \\
\hline High & $525 \pm 91$ & $542 \pm 95$ & $535 \pm 90$ & $30.7 \pm 0.6$ & $31.3 \pm 1.0$ \\
Medium & $407 \pm 12$ & $415 \pm 11$ & $408 \pm 10$ & $30.4 \pm 0.5$ & $31.9 \pm 1.0$ \\
Low & $366 \pm 12$ & $376 \pm 14$ & $367 \pm 13$ & $29.3 \pm 0.9$ & $31.5 \pm 0.8$ \\
\hline
\end{tabular}

IPCC value: $\mathrm{CO}_{2}=350 \mathrm{ppm}$.

Temperature $=23.5^{\circ} \mathrm{C}-25.5^{\circ} \mathrm{C}$.

\subsection{Comparison of Density of Trees, Concentration of $\mathrm{CO}_{2}$ and Temperature at Different Sampling Locations}

Table 3 presents the comparison of density of trees, daily $\mathrm{CO}_{2}$ and temperature at different sampling points. It was found that mean density of trees in low activity areas (234.3 \pm 6.7$)$ was higher compared to those in medium $(22.8 \pm 0.5)$ and high $(24.2 \pm 0.7)$ activity areas respectively. The difference was statistically significant. Also, a statistically significant difference existed between mean concentration of $\mathrm{CO}_{2}$ at high activity area $(534.3 \pm 91.7 \mathrm{ppm})$ compared to medium $(410.2 \pm 10.6 \mathrm{ppm})$ and low $(369.5 \pm 13.7 \mathrm{ppm})$ activity areas. The mean temperature $\left({ }^{\circ} \mathrm{C}\right)$ in the high, medium and low activity areas was $(31.5 \pm 0.6)$, $(31.2 \pm 0.7)$ and $(29.5 \pm 0.8)$ respectively. The difference was statistically significant.

Table 3. Comparison of density of trees, daily $\mathrm{CO}_{2}$ levels and Temperature at different sampling points.

\begin{tabular}{|c|c|c|c|c|}
\hline Parameters (Units) & Location & $\operatorname{Mean} \pm$ SD & F-statistics & p-Value \\
\hline \multirow{3}{*}{ Density of trees (Number of trees) } & High & $24.2 \pm 0.7$ & 35.365 & $<0.001$ \\
\hline & Medium & $22.8 \pm 0.5$ & & \\
\hline & Low & $234.3 \pm 6.7$ & & \\
\hline \multirow[t]{2}{*}{$\mathrm{CO}_{2}(\mathrm{PPM})$} & Medium & $410.2 \pm 10.6$ & 10.363 & 0.001 \\
\hline & Low & $369.5 \pm 13.7$ & & \\
\hline \multirow{2}{*}{ Temperature $\left({ }^{\circ} \mathrm{C}\right)$} & High & $31.5 \pm 0.6$ & & \\
\hline & Low & $29.5 \pm 0.8$ & & \\
\hline
\end{tabular}

Table 4. Correlation matrix of $\mathrm{CO}_{2}$, Temperature and density of trees.

\begin{tabular}{|c|c|c|c|}
\hline Parameters (Units) & $\mathrm{CO}_{2}$ & Temperature & Density of trees \\
\hline Carbon dioxide (PPM) & 1 & & \\
\hline Temperature $\left({ }^{\circ} \mathrm{C}\right)$ & $0.612^{* *}$ & 1 & \\
\hline Density of trees & $-0.456^{*}$ & $-0.724^{* *}$ & 1 \\
\hline
\end{tabular}

**. Correlation is significant at the 0.01 level (2-tailed).

*. Correlation is significant at the 0.05 level (2-tailed). 


\subsection{Spatial Distribution of $\mathrm{CO}_{2}$, Temperature and Density of Trees Within the Sampling Locations}

The spatial distribution of $\mathrm{CO}_{2}$ concentration in relation to temperature and landscaping is depicted in Figures 2, 3 and 4. It was observed that $\mathrm{CO}_{2}$ concentration reduces northward away from the urban core area where there were fewer trees. The areas with low commercial activities had large number of trees while temperature and $\mathrm{CO}_{2}$ flux were lower in these areas. It was observed that few or no trees were found in the high commercial activities zones which could have contributed to the surge in concentration of $\mathrm{CO}_{2}$ and temperature values in the areas. It was found that areas with landscape of trees had lower temperature and $\mathrm{CO}_{2}$, which was as a result of photosynthesis of the trees which sequestrated the $\mathrm{CO}_{2}$ present during the day. The ten most common species, including unidentified dead trees, account for $45.7 \%$ of all trees; while in total, 43 tree species were sampled in Ibadan.

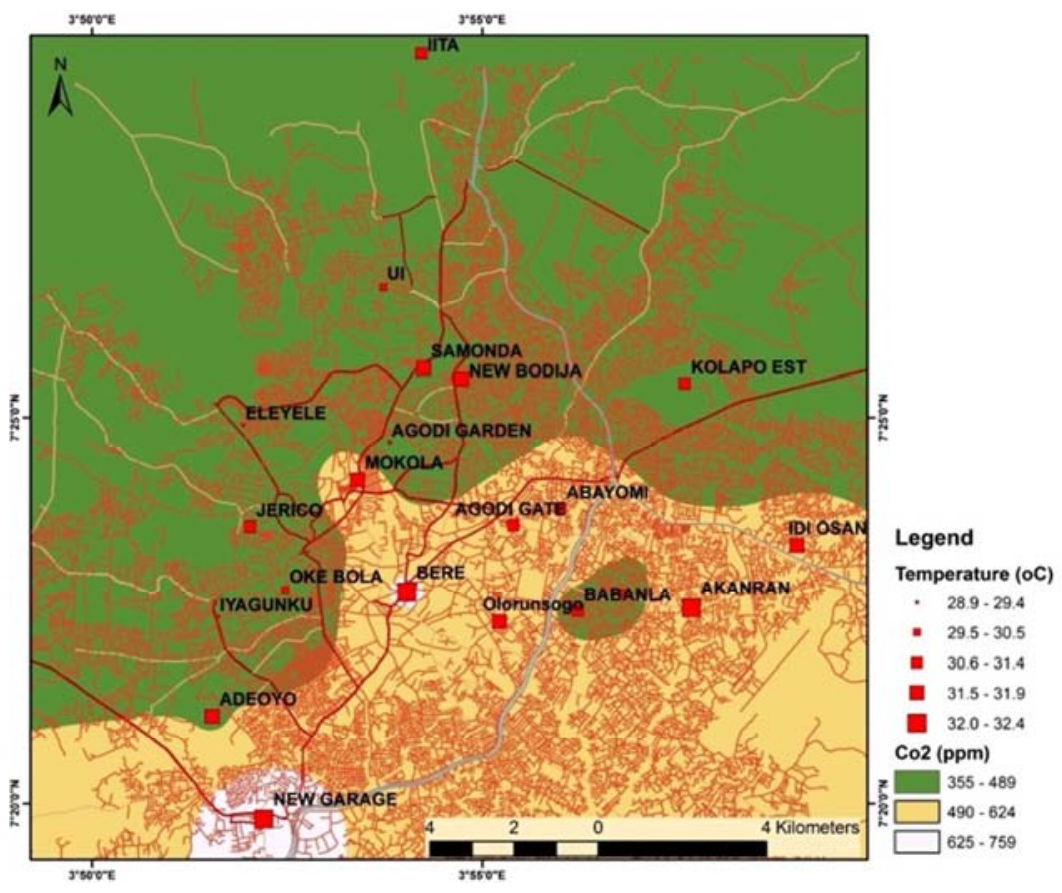

Figure 2. Spatial distribution of $\mathrm{CO}_{2}$ in relation to temperature.

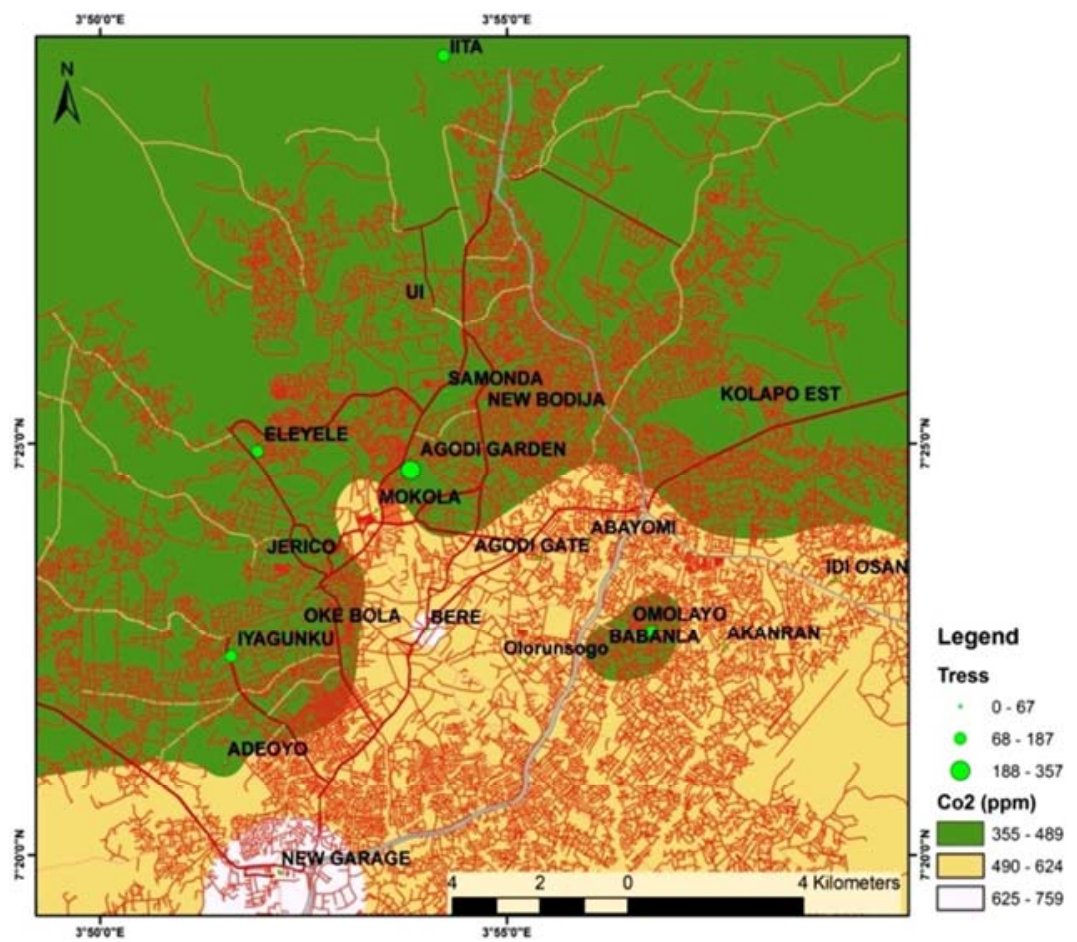

Figure 3. Spatial distribution of $\mathrm{CO}_{2}$ in relation to density of trees. 


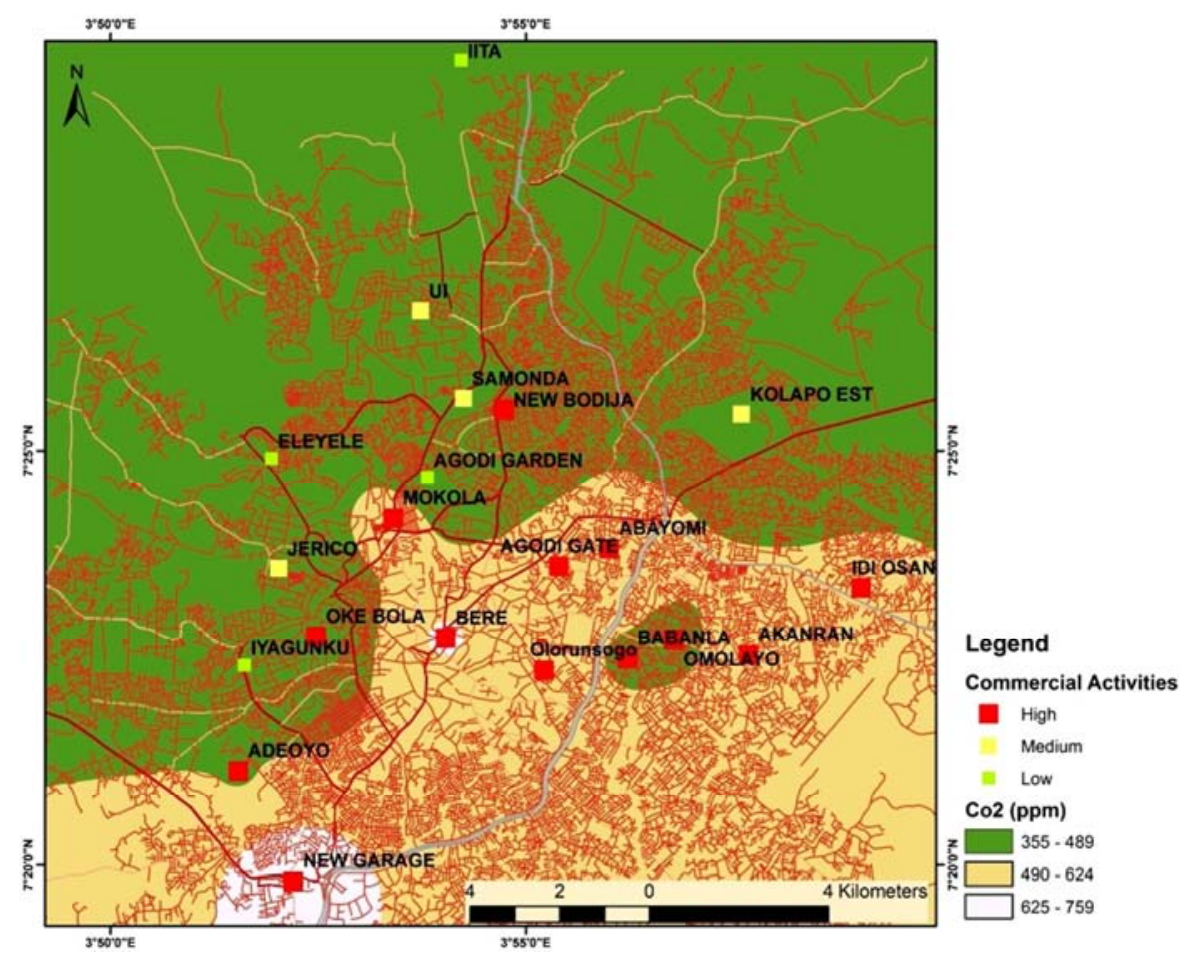

Figure 4. Spatial distribution of $\mathrm{CO}_{2}$ in relation to commercial activities.

\subsection{Regression Model of $\mathrm{CO}_{2}$ Concentration with Temperature and Density of Trees}

Modelling of temperature of the sampling area, density of trees and $\mathrm{CO}_{2}$ concentration was carried out using mutiple regression analysis (Table 5). This was done to ascertain the predictors of $\mathrm{CO}_{2}$ concentration in the study area. The predictor, only density of trees, has a negative regression coefficient (-0.029). This shows a negative regression relation with $\mathrm{CO}_{2}$ concentration which is an indicator of increase in $\mathrm{CO}_{2}$ concentration. However, density of trees has the lowest $\beta$-value (0.592), which goes to show that change in the number of trees or biomass density may not be the only major factor responsible for change in the concentration $\mathrm{CO}_{2}$ in Ibadan. Temperature has the highest $\beta$-value (0.592), indicating that temperature makes the strongest unique contribution to explaining the dependent variable
(Concentration of $\mathrm{CO}_{2}$ ) when the variance explained by all other variables in the model is controlled. Temperature and density of trees contribute significantly in explaining the $\mathrm{CO}_{2}$ concentration $(p=0.015)$. The fitted model is significant. Therefore, the regression equation is represented as:

$$
\mathrm{Qc}=57.9 \mathrm{~T}-0.029 \mathrm{Qt}-1322.238
$$

Where Qc $=$ concentration of carbon dioxide, $\mathrm{T}=$ Temperature, $Q t=$ Number of trees.

Furthermore, a positive relationship was observed between $\mathrm{CO}_{2}$ and temperature as depicted in Figure 5, although the relationship was not significant. Also, Figure 6 revealed that there was an inverse relationship between $\mathrm{CO}_{2}$ and number of trees (biomass density). This indicates that an increase in the density of trees could bring about decrease in the $\mathrm{CO}_{2}$ concentration.

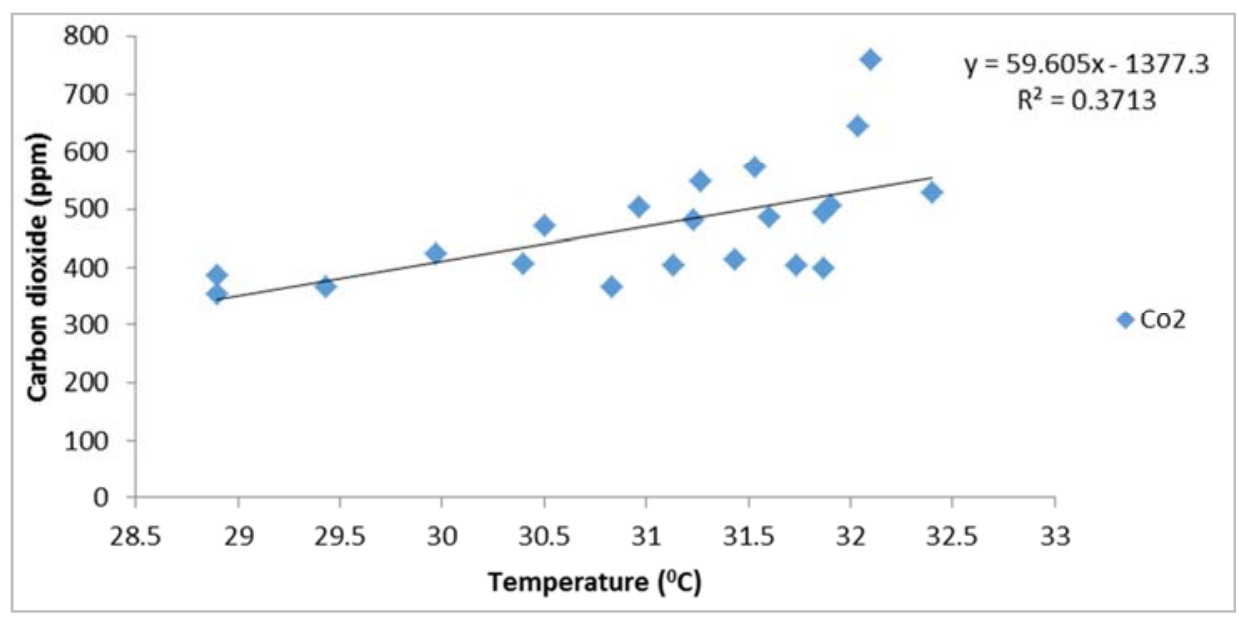

Figure 5. Regression analysis of carbon dioxide and temperature. 


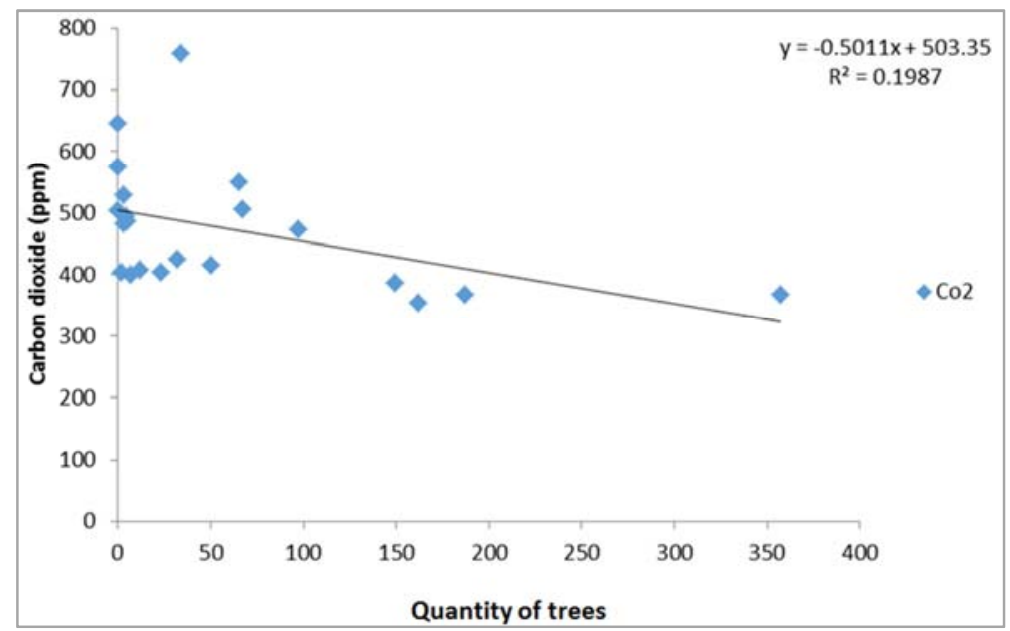

Figure 6. Regression Analysis of Carbon dioxide and Quantity of Trees.

Table 5. Modeling temperature and density of trees as predictors of $\mathrm{CO}_{2}$ concentration.

\begin{tabular}{lllll}
\hline Variables & R square & $\boldsymbol{\alpha}$ (coefficient) & B & F/t (p Value) \\
\hline Concentration of $\mathrm{CO}_{2}$ (Non adjusted) & & & & $5.384(0.015)$ \\
Model & 0.612 & 57.9 & 0.592 & $2.188(0.042)$ \\
Temperature & & -0.029 & -0.027 & $0.101(0.921)$ \\
Density of trees & & 1322.23 & & \\
Constant & & & \\
\hline
\end{tabular}

\section{Discussion}

The study assessed the spatial distribution of carbon dioxide and temperature flux at different landscapes in Ibadan metropolis. The study found that $\mathrm{CO}_{2}$ concentration was higher in the afternoon compared to concentrations in the morning and late evening. Concentration of $\mathrm{CO}_{2}$ among the high, medium and low commercial activity areas exceeded Intergovernmental Panel on Climate Change (IPCC) limit of 350ppm [33]. This is similar to the findings of previous studies $[34,35]$. However, $\mathrm{CO}_{2}$ concentration was higher in high commercial activity areas compared to the medium and low commercial activity areas. This probably could have been due to decreases in $\mathrm{CO}_{2}$ emissions convective mixing when anthropogenic activities were minimal in the study area. It could also be as a result of high density of trees in low commercial activity areas as revealed in this study. These results agree with the assertion of a study that large and periodic variations indicate the stronger daily dependence of the $\mathrm{CO}_{2}$ [36]. During the study period, the average $\mathrm{CO}_{2}$ concentrations varied between 355 and $759 \mathrm{ppm}$, with $19 \%$ of data lying below $400 \mathrm{ppm}, 28.6 \%$ lying in the range $400-500 \mathrm{ppm}$, and $33 \%$ of the data lying above 600 ppm. Maximum frequency of $\mathrm{CO}_{2}$ was observed at 402.5 $\mathrm{ppm}$ during the study period. The study also revealed that temperature was highest during the day at all sampling sites. Also, it was observed that temperature was lower in areas with low to medium commercial activities and landscapes with sufficient density of trees. This corroborates the findings of a study in which lower air temperatures in landscaped areas compared to surrounding un-landscaped areas were found out $[37,38]$. Also, in landscaped areas, temperatures are observed to be usually cooler towards the center than around its edges. One of the previous studies opined that cooler air temperatures achieved from urban landscape can have significant impacts on human health [37]. The concentration of population in urban cities has remained one of the robust contributors of carbon emissions, which may be because of the lack of opportunities in rural areas.

The study found that, in spatial distribution, $\mathrm{CO}_{2}$ concentration reduced northward away from the urban core area where there were fewer trees. Furthermore, the areas with low commercial activities had large number of trees while temperature and $\mathrm{CO}_{2}$ flux were lower in these areas. This indicates that existence of trees in an area has a role to play in the reduction of $\mathrm{CO}_{2}$ concentration and temperature of that particular location. The study found that there is a significant negative relationship between quantity of trees with $\mathrm{CO}_{2}$ concentration and temperature. In areas where there was large quantity of trees such as Agodi Garden, both temperature and $\mathrm{CO}_{2}$ were minimal, while areas characterized with high commercial activities and traffic congestion having minimum trees around (Agodi Gate) had high concentration of $\mathrm{CO}_{2}$. The spatial analysis of the results revealed that $\mathrm{CO}_{2}$ flux increases with urbanization in the study area. More so, the findings of this study agree with a previous report that there were higher values of $\mathrm{CO}_{2}$ concentration, $1780-1840 \mathrm{ppm}$, in heavily congested areas in Kaduna and 1160-530 ppm in Abuja, Nigeria [39]. The benefit of landscaping in pollution removal cannot be overemphasized in the study area. The study has shown that areas where there were minimal number of trees had highest concentration of $\mathrm{CO}_{2}$. A major risk, low number of trees in 
the study area, is health related hazards from poor air quality. Poor air quality has been confirmed to be a common problem in many urban areas [40-42]. It can lead to human health problems, damage to landscape materials and ecosystem processes, and reduced visibility.

Urban landscape plays a major role in reducing the effect of climate change, by sequestering atmospheric carbon (from carbon dioxide) in tissues and by reducing energy use in buildings, and consequently reducing carbon dioxide emissions from fossil-fuel based power plants [43]. This study has found that temperature positively correlates with the $\mathrm{CO}_{2}$ concentration. This shows that increase in temperature could contribute to the increased $\mathrm{CO}_{2}$ concentration. Also, density of trees inversely correlates with the $\mathrm{CO}_{2}$ concentration. This is an indication that increase in density of trees could be attributed to decrease in $\mathrm{CO}_{2}$ concentration. This is similar to the report of a study that $\mathrm{CO}_{2}$ concentration could be reduced to a certain extent through decreasing impervious surface cover and increasing vegetation coverage [44]. The prediction model established in this study relates $\mathrm{CO}_{2}$ concentration with temperature and number or density of trees. This study found that temperature and density of trees predicts change in $\mathrm{CO}_{2}$ concentration in the study area. The findings revealed that each of the above stated variables contributes significantly as independent variables in explaining $\mathrm{CO}_{2}$ concentration. A study had shown that urban landscaping in form of afforestation improves air quality through reduction in air temperature and direct pollutants removal from air [42]. Also, integrative studies on trees planting have revealed that an increase in tree cover leads to reduced ozone formation [24].

\section{Conclusion}

Human exposure to air pollutants poses severe health problems especially in urban areas where pollution levels are on the increase. The study revealed that daily $\mathrm{CO}_{2}$ concentrations and temperature were higher than IPCC recommended value, but higher in the afternoon compared to the value obtained in the morning and evening periods. The prediction model established in this study relates $\mathrm{CO}_{2}$ concentration with temperature and quantity/number of trees. This study found that temperature and density of trees predicted change in $\mathrm{CO}_{2}$ concentration in the study area. Each of temperature and density of trees contributes significantly as independent variables in explaining $\mathrm{CO}_{2}$ concentration. Majority of the areas with high commercial activities in Ibadan metropolis had little or no parks where trees are planted. Temperature was positively correlated with the $\mathrm{CO}_{2}$ concentration while density of trees was inversely correlated with the $\mathrm{CO}_{2}$ concentration. These findings indicate that increase in density of trees could be attributed to decrease in the $\mathrm{CO}_{2}$ concentration. Hence, tree planting as an important component of landscaping to reduce air pollutants at source needs to be encouraged in an urban center, particularly in the urban core of Ibadan metropolis.

\section{Acknowledgements}

The authors wish to acknowledge the contributions of community heads in all the sampling locations and the field staff.

\section{References}

[1] Evelyn M. I. and T. T. Tyav, (2013) Environmental Pollution in Nigeria: The Need for Awareness creation for sustainable Development. Journal of Research in forestry, Wildlife and Environment, 4. 2, 5-14.

[2] Ekuri, P. and E. B. Eze, (1999) "Teaching Environmental Pollution in Primary/secondary schools" Workshop paper, on the orientation workshop for teachers on the implementation of the National environmental education curricula at Ogoja, in October, 1999.

[3] Jande, G. G. (2005) Legal Mechanisms for the control of Pollution on the high seas, Pp. 1-13, in the African Journal of Environmental Law and Development Studies, Vol 1. Part 1.

[4] Anastasia D. and Vasilia C. (2011) Causes and Consequences of Air Pollution and Environmental Injustice as Critical Issues for Science and Environmental Education, The Impact of Air Pollution on Health, Economy, Environment and Agricultural Sources, Dr. Mohamed Khallaf (Ed.), ISBN: 978-953-307528-0, InTech.

[5] Commission of the European Communities (CEC) (2006). Cohesion Policy and cities: the urban contribution to growth and jobs in the regions. COM (2005) 718 Copenhagen, EEA.

[6] US Environmental Protection Agency (EPA) (2007) Terms of environment. Office of Communications, Education, and Public Affairs, Washington DC.

[7] Iyoha, M. A. (2009) The Environmental effects of oil industry activities on the Nigerian Economy: A theoretical analysis. Paper Presented at National Conference on the management of Nigeria's Petroleum Resources, Organised by the Department of Economics, Delta State University.

[8] Pilson, M. E. Q. (1998) An Introduction to the Chemistry of the Sea. Prentice Hall, Upper Saddle River, NJ, 431 pp.

[9] Houghton, R. A. (2003) Revised estimates of the annual net flux of carbon to the atmosphere from changes in land use and land management 1850-2000. Tellus. 55B. 2, 378-390.

[10] Le Treut, H., Sommerville, R., Cubasch, U., Ding, Y., Mauritzen, C., Mokssit, A., Peterson, T. and M. Prather, (2007) Historical overview of climate change science, 93127. In Soloman, S., D. Qin, M. Manning, Z. Chen, M. Marquis, K. B. Averyt, M. Tignor, and H. L. Miller (eds.), Climate Change 2007: The Physical Science Basis. Contributions of Working Group I to the Fourth Assessment Report of the Intergovernmental Panel on Climate Change. Cambridge University Press, Cambridge, UK and New York, NY.

[11] Eszter, T. (2011) Soil Carbon-Dioxide Emission Measurements in Different Soil Use Systems. Thesis of PhD Dissertation Submitted in the Department of Soil Science and Water Management. Corvinus University of Budapest. 
[12] Majumdar, D., Rao, P. and N. Maske, (2017) Inter-seasonal and spatial distribution of ground-level greenhouse gases $(\mathrm{CO} 2, \mathrm{CH} 4, \mathrm{~N} 2 \mathrm{O})$ over Nagpur in India and their management roadmap. Environ. Monit. Assess. 189, 121. DOI $10.1007 / \mathrm{s} 10661-017-5829-2$.

[13] MacFarling Meure, C. D. Etheridge, C. Trudinger, P. Steele, R. Lagenfelds, T. van Ommen, A. Smith and J. Elkins, (2006) Law dome $\mathrm{CO} 2, \mathrm{CH} 4$ and $\mathrm{N} 2 \mathrm{O}$ ice core records extended to 2000 years BP. Geophysical Research Letters. 33, L14810. doi: 10.1029/2006GL026152.

[14] WMO, (2016) Greenhouse Gas Bulletin: The State of Greenhouse Gases in the Atmosphere Based on Global Observations through 2015.

[15] Gao, Y.; Lee, X.; Liu, S.; Hu, N.; Wei, X.; Hu, C.; Liu, C.; Zhang, Z. and Y. Yang, (2018) Spatiotemporal variability of the near-surface $\mathrm{CO} 2$ concentration across an industrial-urbanrural transect, Nanjing, China. Science of The Total Environment, 631-632, 1192.

[16] Ciais, P., Sabine, C., Bala, G., Bopp, L., Brovkin, V., Canadell, J., Chhabra, A., DeFries, R., Galloway, J., Heimann, M., Jones, C., Quere, C., Myneni, R., Piao, S., and P. Thornton, (2013) Carbon and Other Biogeochemical Cycles, book section 6, Cambridge University Press, Cambridge, United Kingdom and New York, NY, USA, 465-570, doi: 10.1017/CBO9781107415324.015.

[17] Denman, K. L., G. Brasseur, A. Chidthaisong, P. Ciais, P. M. Cox, R. E. Dickinson, D. Hauglustaine, C. Heinze, E. Holland, D. Jacob, U. Lohmann, S. Ramachandran, P. L. da Silva Dias, S. C. Wofsy, and X. Zhang, (2007) Couplings between changes in the climate system and biogeochemistry, 499-587. In Soloman, S., D. Qin, M. Manning, Z. Chen, M. Marquis, K. B. Averyt, M. Tignor, and H. L. Miller (eds.), Climate Change 2007: The Physical Science Basis. Contributions of Working Group I to the Fourth Assessment Report of the Intergovernmental Panel on Climate Change. Cambridge University Press, Cambridge, UK and New York, NY.

[18] Meehl, G. A., T. F. Stocker, W. D. Collins, P. Friedlingstein, A. T. Gaye, J. M. Gregory, A. Kitoh, R. Knutti, J. M. Murphy, A. Noda, S. C. B. Raper, I. G. Waterson, A. J. Weaver, and Z.-C. Zhao, (2007) Global climate projections, 747-845. In S. Soloman, D. Qin, M. Manning, Z. Chen, M. Marquis, K. B. Averyt, M. Tignor, and H. L. Miller (eds.), Climate Change 2007: The Physical Science Basis. Contributions of Working Group I to the Fourth Assessment Report of the Intergovernmental Panel on Climate Change. Cambridge University Press, Cambridge, UK and New York, NY.

[19] Poumanyvong, P. and S. Kaveko, (2010) Does urbanization lead to less energy use and lower $\mathrm{CO} 2$ emissions? A crosscountry analysis. Ecological Economics, 70, 434-444.

[20] Jerome Abesamis, Jumel Carlo Campos and Cecille Castell, 2013. Estimating the effects of Urbanization on carbon emissions: Evidence in the Philippines. Young Economists' Perspective. 7.1, 1-4.

[21] Jacobson, T. A.; Kler, J. S.; Hernke, M. T.; Braun, R. K.; Meyer, K. C. and W. E. Funk, (2019) Direct human health risks of increased atmospheric carbon dioxide. Nature Sustainability. doi: https://doi.org/10.1038/s41893-0190323-1.

[22] Beheshti, A., Cekanaviciute, E., Smith, D. J. and S. V. Costes, (2018) Global transcriptomic analysis suggests carbon dioxide as an environmental stressor in spaceflight: a systems biology GeneLab case study. Sci. Rep. 8, 4191.

[23] Raciti, S. M.; Hutyra, L. R. and J. D. Newell, (2014) Mapping carbon storage in urban trees with multi-source remote sensing data: Relationships between biomass, land use, and demographics in Boston neighborhoods. Science of The Total Environment, 500-501, 72-83.

[24] Nowak D. J. and J. F. Dwyer, (2000) Understanding the benefits and costs of urban forest ecosystems. In: Kuser, John E., ed. Handbook of urban and community forestry in the northeast. New York: Kluwer Academics/Plenum: 1122.

[25] National Bureau of Statistics (2006) Nigeria Provisional result of the 2006 Population Census www.nigerianstat.gov.ng/Connections/Pop2006.pdf.

[26] UNDESA. (2012) World Urbanization Prospects: The 2011 Revision, United Nations Departments of Economic and Social Affairs (UNDESA), Population Division, April 2011.

[27] Areola O. (1992) The spatial growth of Ibadan city and its impact on rural hinterland in Ibadan region. Ibadan: Rex Charles and Conne publications 98-106.

[28] Ipingbemi, O. (2010) Travel characteristics and mobility constraints of elderly in Ibadan. Journal of Transport Geography. $\quad 18.2$ 285-291. doi.org/10.1016/j.jtrangeo.2009.05.011.

[29] Waller, L. A. and C. A. Gotway, (2004) Applied Spatial Analysis of Public Health Data. Hoboken NJ: John Wiley \& Sons.

[30] Srivastava A, Nagpal B. N., Saxena R., Eapen A., Ravindran K. J., Subbarao S. K., RajamanikamC., Palanisamy M., Kalra N. L. and N. C. Appavoo, (2003) GIS based malaria information management system for urban malaria scheme in India. Computer Methods and Programs in Biomedicine, 71.1, 63-75.

[31] Hochadel, M., Heinrich, J., Gehring, U., Morgenstern, V., Kuhlbusch, T., Link, E., Wichmann, H. E. and U. Kramer, (2006) Predicting long-term average concentrations of trafficrelated air pollutants using GIS based information. Atmospheric Environment 40, 542-553. doi.org/10.1016/j.atmosenv.2005.09.067.

[32] Künzli N, Jerrett M, Mack WJ, Beckerman B, LaBree L, Gilliland F, Thomas D, Peters J, H. N. Hodis, (2005) Ambient air pollution and atherosclerosis in Los Angeles. Environmental Health Perspectives. 113.2, 201-206. doi: 10.1289/ehp.7523.

[33] IPCC. (2007) Climate Change 2007: Mitigation. Contribution of Working Group III to the Fourth Assessment Report of the Intergovernmental Panel on Climate Change [B. Metz, O. R. Davidson, P. R. Bosch, R. Dave, L. A. Meyer (eds)], Cambridge University Press, Cambridge, United Kingdom and New York, NY, USA., 851 pp. http://www.ipcc.ch/publications_and_data/publications_ipcc_f ourth_assessment_report_wg3 report mitigation_of_climate change.htm (aceeseed on $17 / 0 \overline{5} / 18$ ).

[34] Ogunlesi D. O., Adejumo M., Sridhar M. K. C. and A. O. Coker, (2018) Assessment of Selective Air Quality Parameters in an Industrial Layout and a Residential Settlement within Ibadan, Nigeria. International Journal of Environmental Monitoring and Analysis. 6. 6, 144-151. doi: 10.11648/j.ijema.20180606.11. 
[35] Ward, H. C., Kotthaus, S., Grimmond, C. S. B., Bjorkegren, A., Wilkinson, M., Morrison, W. T. J., Evans, J. G., Morison, J. I. L. and M. Iamarino, (2015) Effects of urban density on carbon dioxide exchanges: observations of dense urban, suburban and woodland areas of southern England. Environmental Pollution, 198, 186-200. ISSN 02697491, doi: https://doi.org/10.1016/j.envpol.2014.12.031.

[36] Chandra, N., Lal, S., Venkataramani, S., Patra, P. K., and V. Sheel, (2016) Temporal variations of atmospheric CO2 and $\mathrm{CO}$ at Ahmedabad in western India, Atmos. Chem. Phys., 16, 6153-6173. doi.org/10.5194/acp-16-6153-2016, 2016.

[37] Nowak, J. and G. Heisler, (2010) Air Quality Effects of Urban Trees and Parks. Research Series Monograph. Ashburn, VA: National Recreation and Parks Association Research Series Monograph. $44 \mathrm{p}$.

[38] Edmondson, J. L.; Stott, I.; Davies, Z. G.; Gaston, K. J. and J. R. Leake, (2016) Soil surface temperatures reveal moderation of the urban heat island effect by trees and shrubs. Scientific Reports, 6, 33708; doi: 10.1038/srep33708.

[39] Akpan, U. G. and P. N. Ndoke, (1999). Contribution of vehicular traffic emission to $\mathrm{CO} 2$ emission in Kaduna and Abuja, Nigeria. Leonardo Electronic Journal of Practices and Technologies. p. 81-90.
[40] Ana, G. R. E. E. and M. K. C. Sridhar, (2009) Industrial emissions and health hazards among selected factory workers at Eleme, Nigeria, Journal of Environmental Health Research, UK., 9.1, 43-51.

[41] Ana, G. R. E. E., Sridhar M. K. C. and M. C. Asuzu, (2010) Environmental risk factors and hospital-based cancers in two Nigerian cities, Journal of Public Health and Epidemiology 2.8, 216-223.

[42] Nowak, David J.; Hoehn, Robert E. III; Crane, Daniel E.; Stevens, Jack C.; Leblanc Fisher, Cherie. (2010) Assessing urban forest effects and values, Chicago's urban forest. Resour. Bull. NRS-37. Newtown Square, PA: U.S. Department of Agriculture, Forest Service, Northern Research Station. 27 p.

[43] Abdollahi, K. K.; Ning, Z. H. and A. Appeaning, eds. (2000) Global climate change and the urban forest. Baton Rouge, LA: GCRCC and Franklin Press. 77 p.

[44] Liu, M.; Zhu, X.; Pan, C.; Chen, L.; Zhang, H.; Jia, W. and W. Xiang, (2016) Spatial variation of near-surface CO2 concentration during spring in Shanghai. Atmospheric Pollution Research, 7, 31-39. 